\title{
Análise do conto Missa do galo, de Machado de Assis
}

Ariel Engel Pesso

"Nunca pude entender a conversação que tive com uma senhora, há muito anos,

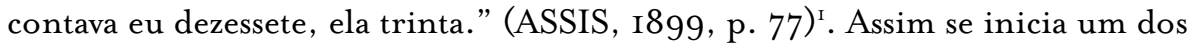
contos mais conhecidos e emblemáticos de Machado de Assis: Missa do galo. Nogueira, já velho, é o narrador em primeira pessoa que nos conta, de forma um tanto quanto enigmática, uma passagem de sua juventude, quando foi morar no Rio de Janeiro, na casa de Meneses, marido de uma prima que falecera, junto com Conceição, sua mãe e duas escravas - a família pequena é uma constante na obra machadiana (STEIN, 1984).

O conto segue a "receita" do conto moderno, inaugurado com Edgar Allan Poe, no qual se destacam a brevidade e "algo" nas entrelinhas. Apesar de não seguir à risca a estrutura o conto clássico, tal qual em Quiroga ou Tchekhov (uma história revelada em primeiro plano e uma história velada em segundo) (PIGLIA, 2004), o que nos impressiona nessa narrativa machadiana é o que acontece, ou melhor, o que não acontece. É como se o momento da narrativa nos escapasse por entre as mãos e, mesmo após su-

I Todos os trechos do conto foram retirados da obra original Páginas Recolhidas, de Machado de Assis, disponível digitalmente no site da Biblioteca Brasiliana. Cf. ASSIS, I899. 
cessivas releituras, um quê de sensualidade, sexualidade e indignação ainda percorresse nossa mente - é o conto como "autarquia" a que se refere Julio Cortázar ${ }^{2}$. Ainda, a semelhança entre Machado e o contista russo salta aos olhos: não apenas na temática dos contos (como na comparação entre $O$ alienista, do brasileiro, e Enfermaria $n^{0} 6$, de Tchekhov), mas também na estilística e na construção da narrativa.

A figura feminina assume um papel central na obra de Machado de Assis. O conto Missa do Galo permite extrair, metonimicamente, suas principais características: o casamento como instituição basilar da sociedade brasileira oitocentista, visto como "carreira" para a mulher (tal qual a vida profissional ou política era para o homem) e no seio do qual ocorria a maternidade e a fidelidade, aqui entendida em sentido duplo: a mulher deveria manter a fidelidade e relacionar-se apenas e tão somente com seu marido, evitando relações sexuais anteriores ao matrimônio e, em sua constância, evitando relacionar-se com outros homens. O homem, por sua vez, parecia gozar de certo prestígio na traição, sendo essa uma prática recorrente na sociedade da época - ele comumente traía a esposa com mulheres de classes mais baixas, como prostitutas e escravas. Supunha-se, ainda, que o homem possuía uma sexualidade mais desenvolvida que a mulher, e a questão da paternidade era muito importante - assegurar que a esposa não se relacionasse com outros para, assim, ter a certeza de que a prole seria sua. À mulher que não se cassasse restava apenas uma de três possibilidades: a solteirice, o convento ou o magistério (STEIN, I984).

Mas voltemos ao conto. Não devemos perder de vista o fato de a história ser narrada em primeira pessoa e, mais, de o narrador ser um "eu" que rememora fatos de um passado longínquo e, por isso, pode ter a sua memória comprometida: "Há impressões dessa noite que me aparecem truncadas ou confusas. Contradigo-me, atrapalho-me" (ASSIS, I899, p. 84-85). Em realidade, o conto parece mais um ato de uma peça de teatro na qual fica a cargo do espectador preencher as possíveis lacunas deixadas pelo enredo ${ }^{3}$. Tal qual ocorre em Dom Casmurro e Memórias Póstumas de Brás Cubas, deve-se sempre desconfiar do relato (mais no primeiro livro do que no segundo).

2 "O indício de um grande conto está para mim no que poderíamos chamar a sua autarquia, o fato de que a narrativa se tenha desprendido do autor como uma bolha de sabão do pito de gesso." (CORTÁZAR, I974, p. 229-230).

3 Sobre a aproximação entre este conto e o teatro, ver Carvalho, I990. 
A parte inicial é calma: há a apresentação das personagens e do ambiente em que vivem. Ficamos sabendo o nome do protagonista apenas no sétimo parágrafo. Família pequena, costume velhos - dez e meia todos já dormiam. É noite de Natal e Nogueira resolveu ficar na Corte para ir à missa do galo; Meneses "fora ao teatro", um eufemismo para sua escapada semanal em que dormia com a amante, uma senhora separada do marido.

Sua esposa, Conceição, de início é ilustrada como uma "santa". Incomodou-se com a existência da amante, mas "resignara-se, acostumara-se, e acabou achando que era muito direito" (ASSIS, I899, p. 78). Tinha um comportamento moderado; no capítulo em questão, é caracterizada como maometana: "aceitaria um harém, com as aparências salvas" (ASSIS, I899, p. 78). Era uma pessoa simpática, cujo rosto mediano não era nem bonito nem feio - "não sabia odiar; pode ser até que não soubesse amar" (ASSIS, I899, p. 78).

Como o narrador combinara de acordar o vizinho para ambos irem à missa, resolveu ler Os três mosqueteiros para passar o tempo. Quando já estava ébrio de Dumas, eis que ouve um pequeno rumor acordá-lo da leitura: era Conceição, cujo vulto assomou à porta da sala. Sua chegada é uma espécie de inauguração da cena: ambos os significantes possuem significados que não são despropositados - "assomar" significa "subir, elevar-se a um lugar mais alto, extremo" e vulto significa "aquilo que é notável, que tem grande importância" (GOULART, 2008, p. I64-I65).

Conceição nega que acordou pelo barulho da sala, mas Nogueira duvida da afirmativa. Mais tarde, ela mesma se contradiz ao negar que possuía o sono leve. É uma das muitas contradições, não sabemos se dela ou do narrador. Após a mulher entrar na sala, desenrola-se uma conversa monótona, como que de praxe entre dois estranhos em uma noite de Natal: falam sobre a paciência do rapaz e os romances que leram; a menção de Os três mosqueteiros e $A$ moreninha parece indicar uma crítica ao modelo feminino puro do romantismo (GUNHA, 2006).

Quando ele acaba de falar e ela endireita a cabeça, cruza os dedos e sobre eles pousa o queixo, "tendo os cotovelos nos braços da cadeira, tudo sem desviar de mim os grandes olhos espertos" (ASSIS, I899, p. 8I); a história começa a adquirir uma certa aura de sexualidade. $\mathrm{O}$ conto parece tomar o rumo de uma sensualidade velada, principalmente no seguinte trecho:

Pouco a pouco, tinha-se reclinado; fincara os cotovelos no mármore da mesa e metera o rosto entre as mãos espalmadas. Não estando abotoadas as mangas, caíram naturalmente, e eu vi-lhe metade dos braços, muito claros, e menos ma- 
gros do que se poderiam supor. A vista não era nova para mim, posto também não fosse comum; naquele momento, porém, a impressão que tive foi grande. As veias eram tão azuis, que apesar da pouca claridade, podia contá-las do meu lugar (ASSIS, I899, p. 82).

Tanto é assim que ela ocupa oito lugares distintos, tal qual uma coreografia de balé 4 . A própria impressão do narrador muda: se antes Conceição era santa, agora ela é boa, muito boa; se era simpática, agora é linda, lindíssima - vejamos que ela não é; ela fica, portanto torna-se. Se, antes, estava ébrio de Dumas, agora parece estar ébrio de Conceição. É interessante notarmos a passividade e calma com que, no dia seguinte, ela ouve o relato do jovem sobre a missa da noite passada - sua caracterização, inclusive, volta a ser "natural, benigna, sem que nada fizesse lembrar a conversação da véspera" (ASSIS, I899, p. 88). Ao descrevê-la como benigna no dia seguinte, o autor (já maduro) nos insinua que na véspera ela fora maligna (CUNHA, 2006).

Não parece ser por acaso que Conceição é identificada com Cleópatra: "Os quadros falavam do principal negócio deste homem [Meneses]. Um representava 'Cleópatra; não me recordo o assunto do outro, mas eram mulheres'” (ASSIS, I899, p. 85). Ora, o único quadro que permanece na mente de Nogueira é, justamente, o que reflete a mulher enigmática, e isso não parece ser uma escolha inocente de Machado. A presença shakespeariana na obra do autor é um fato notório, sendo Otelo a inspiração e a chave de leitura para Dom Casmurro. Assim, há que se mencionar a obra Antônio e Cleópatra, que, segundo o crítico Harold Bloom (200I, p. 666), é a "mais complexa e impressionante" representação feminina de Shakespeare. Sua beleza e sensualidade estão registradas no discurso de Enobarbo: "A idade não consegue fazê-la murchar, nem o hábito estiola/ a sua variedade infinita: outras mulheres saciam/ os apetites que alimentam, mas ela desperta mais fome/ onde traz mais satisfação" (II, ii) ${ }^{5}$.

É de se estranhar que, logo após o único contato físico entre as personagens, Conceição "estremeceu, como se tivesse um arrepio de frio" (ASSIS, I889, p. 85). É quase como uma assunção de culpa em face de

4 Essa ideia é de Marta de Senna. Cf. Rouanet et al., 2008, p. 239-240.

5 Segundo a tradução de Marta de Senna. No original: "Age cannot wither her, nor custom stale/ Her infinite variety: other woman cloy/ The appetites they feed, but she makes hungry/ Where most she satisfies" Cf. Rouanet et al., 2008, p. 238. 
um adultério iminente ${ }^{6}$. Pode-se pensar que o arrepio foi ocasionado pelo arrependimento, mas Conceição parece insistir até que batam na janela anunciando a missa. $\mathrm{O}$ adultério também é insinuado no final do conto, ao mencionar-se o casamento dela com o escrevente juramentado do marido (que falecera).

\section{Referências}

ASSIS, M. Páginas recolhidas. Rio de Janeiro: H. Garnier, Livreiro-Editor, I899. p. 77-88. Disponível em: 〈https://goo.gl/jfWWUa〉. Acesso em: I dez. 2015.

BLOOM, H. Shakespeare: a invenção do humano. Tradução de José Roberto O'Shea. Rio de Janeiro: Objetiva, 200I.

BOSI, A. Machado de Assis: o enigma do olhar. 4. ed. São Paulo: WMF Martins Fontes, 2007.

GARVALHO, L. H. O. V.; WISNIK, J. M. S. (Orient.). Mulher em cena: cenas de amor e morte na ficção brasileira. I990. $240 \mathrm{f}$. Tese (Doutorado em Literatura Brasileira) - Faculdade de Filosofia, Letras e Giências Humanas, Universidade de São Paulo, São Paulo, I990.

GORTÁZAR, J. Valise de Cronópio. Tradução de David Arrigucci Jr. e João Alexandre Barbosa. São Paulo: Perspectiva, I974. p. 227-237.

GUNHA, C. A. Tristezas de uma geração que termina. Teresa: revista de literatura brasileira, São Paulo, v. 6, n. 7, p. 3I-35, 2006.

GOULART, A. T. O jogo da serpente na "Missa do galo". In: FANTINI, M. Crônicas da antiga corte: literatura e memória em Machado de Assis. Belo Horizonte: Editora UFMG, 2008.

PIGLIA, R. Formas breves. Tradução de José Marcos Mariani de Macedo. São Paulo: Companhia das Letras, 2004.

6 Não concordamos com a interpretação de Audemaro Taranto Goulart, para quem esse episódio é uma "autêntica manifestação do orgasmo que toma conta de Conceição", cujas " nítidas indicações de um estado de lassidão, de um torpor pós-orgástico" seriam deduzidas dos seguintes trechos: "Não tinha os grandes olhos compridos, e entrou a olhar à toa para as paredes"; "Conceição parecia esta devaneando" (Conceição) e "Concordei, para dizer alguma coisa, para sair da espécie de sono magnético, ou o que quer que era aquilo que me tolhia a língua e os sentidos"; "O rumor único e escasso era um roer de camundongo no gabinete, que me acordou daquela espécie de sonolência" (Nogueira) (GOULART, 2008, p. I78-I79). 
Análise do conto Missa do galo, de Machado de Assis

RIEDEL, D. C. Metáfora: o espelho de Machado de Assis. Rio de Janeiro: Francisco Alves, 1974.

ROUANET, S. P. et al. Machado de Assis: cinco contos comentados. Rio de Janeiro:

Edições Casa de Rui Barbosa, 2008. p. 209-242.

STEIN, I. Figuras femininas em Machado de Assis. Rio de Janeiro: Paz e Terra, I984.

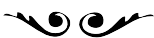

Ariel Engel Pesso é granduando em Letras pela Universidade de São Paulo.

ariel.epesso@gmail.com 